\title{
Ten Years After the Great Recession Began, U.S. Birth Rate Is at Record Low
}

Kenneth M. Johnson

$\mathrm{R}$ ecent National Center for Health Statistics data show a record low birth rate in the United States, and no evidence of any upturn in this birth rate. Though other social and economic factors may also be influencing U.S. birth rates, the impact of the Great Recession persists. I estimate that in 2017, there were 700,000 fewer births in the United States than would have been expected had pre-recessionary birth rates continued among current women of childbearing age. The longer-term impact of the recession is reflected in the 4.8 million fewer births in the United States between 2008 and 2017 than would have been expected given pre-recession trends. Though there are more women of prime childbearing age now than in 2007, there are significantly fewer births. And nearly 2.1 million more women than expected have yet to give birth to their first child. A critical question now is: how many of these 4.8 million births are just delayed, and how many will be foregone entirely?

\section{ACTUAL BIRTHS COMPARED TO BIRTHS USING 2007 BIRTH RATES, 2007 TO 2017}

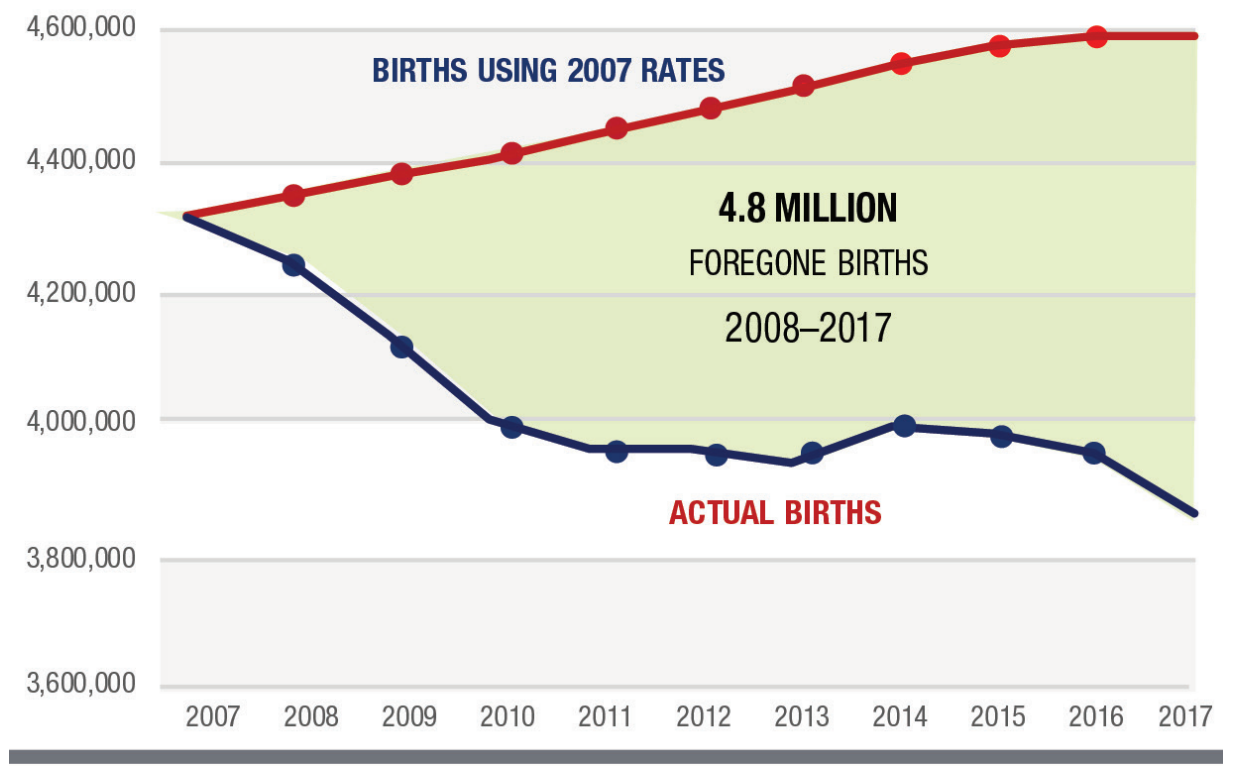

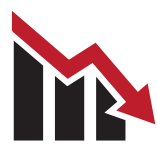

Ten years after the Great Recession began, U.S. fertility continues to decline.

\section{See Related Publications at carsey.unh.edu}

- June 30 2017, Data Snapshot: New data Show U.S. Birth Rates Hit Record Low

December 12 2017: Data Snapshot: 2.1 Million More Childless U.S. Women Than Anticipated

\section{About the Author \\ Kenneth M. Johnson is senior demographer at the Carsey School of Public Policy, professor of sociology at the University of New Hampshire, and an Andrew Carnegie Fellow.}

Huddleston Hall • 73 Main Street • Durham, NH 03824 This piece is printed on Mohawk $100 \%$ recycled paper carsey.unh.edu • 603.862.2821

TTY USERS: DIAL 7-1-1 OR 1-800-735-2964 (RELAY N.H.) 